\title{
Efficacy of peloidotherapy in unilateral plantar fasciitis: A pilot study
}

\author{
Fatih Karaarslan ${ }^{1}\left(\mathbb{0}\right.$, Banu Ordahan ${ }^{2}(0)$ \\ ${ }^{1}$ Department of Medical Ecology and Hydroclimatology, University of Health Sciences, Gülhane Faculty of Medicine, Ankara, Turkey \\ ${ }^{2}$ Department of Physical Medicine and Rehabilitation, Necmettin Erbakan University, Meram Faculty of Medicine, Konya, Turkey
}

Received: May 04, 2020 Accepted: October 06, 2020 Published online: December 01, 2021

\begin{abstract}
Objectives: The aim of this study was to investigate the efficacy of peloidotherapy on pain, functional status, and quality of life (QoL) in patients with unilateral plantar fasciitis (PF).

Patients and methods: This prospective, observational pilot study included a total of 80 patients (13 males, 67 females; mean age: $47.7 \pm 9.9$ years; range, 28 to 68 years) with a diagnosis of unilateral PF between April 2018 and October 2018. The patients were divided into two equal groups. The study group $(n=40)$ received peloidotherapy (five days per week for two weeks, total of 10 sessions) + Achilles tendon and plantar fascia stretching exercises (self-stretching for two weeks twice per day for 30 sec, 10 repeats) + heel cup treatment. The control group $(n=40)$ received Achilles tendon and plantar fascia stretching exercises + heel cup treatment. The patients were evaluated before and after treatment using the Visual Analog Scale-pain (VAS-pain), Foot and Ankle Outcome Scores (FAOS), and Heel Tenderness Index (HTI).

Results: The study group showed statistically significant improvements for all parameters after treatment compared to baseline ( $\mathrm{p}<0.05)$. Control group showed statistically significant improvements in the VAS-pain, HTI, and FAOS-QoL subscales after treatment compared to baseline $(\mathrm{p}<0.05)$. The study group had a better improvement in the VAS-pain, FAOS-pain, and FAOS-work daily life subscales than the control group $(\mathrm{p}<0.05)$.
\end{abstract}

Conclusion: These results indicate that peloidotherapy may be effective in reducing pain and improving functional status and QoL for patients with unilateral PF.

Keywords: Heel pain, peloidotherapy, plantar fasciitis, stretching exercise.

Plantar fasciitis (PF) is one of the most widespread causes of heel pain in adults. The lifelong incidence is $10 \%$, with an increasing incidence among women from 40 to 60 years of age. It can be also named as heel spur syndrome or painful heel syndrome. ${ }^{[1,2]}$ Although its etiology is not fully known, limited ankle dorsiflexion, increased body mass index, long durations standing, overwork, sedentary life styles, pes cavus, pes planus, strained Achilles tendon and intrinsic foot muscles have been implicated. ${ }^{[3,4]}$ For diagnosis, examination findings are critical with patient history and presence of risk factors. The first symptom is sharp pain like a knife stab on the proximal medioplantar face of the foot when standing from bed in the mornings. The pain may reduce within a few steps; however, worsening at the end of the day is typical. Physical examination findings are limited, with an important finding sensitivity during palpation of the site where the proximal plantar fascia adheres to the anteromedial calcaneus. $^{[1,3]}$

Conservative treatment is the first-line treatment of choice. Plantar fasciitis is a condition that is self-limiting and no matter what treatment is given,

Corresponding author: Fatih Karaarslan, MD. SBÜ, Gülhane Tıp Fakültesi, Tıbbi Ekoloji ve Hidroklimatoloji Anabilim Dalı, 06010 Keçiören, Ankara, Türkiye. e-mail: fatih.karaarslan@sbu.edu.tr 
it usually resolves within a year. Of patients, $90 \%$ benefit from conservative treatments. ${ }^{[3]}$ With the conservative approach, invasive treatments include corticosteroid injections, botulinum toxin injections, platelet-rich plasma injections, and dry needling. Noninvasive treatments include oral acetaminophen or non-steroidal anti-inflammatory drugs, plantar fascia stretching exercises, heel cups, orthoses, physical therapy, and extracorporeal shockwave therapy. ${ }^{[3-5]}$ Additionally, kinesiotape, ultrasound treatment, prolotherapy, manual therapy, and dry cupping therapy are the other modalities to reduce pain and provide functional healing in PF patients. ${ }^{[6-10]}$ One of the non-invasive methods used for conservative treatment of $\mathrm{PF}$ is peloidotherapy which is commonly used for many disorders caused by musculoskeletal system diseases. Plantar fasciitis is one of the areas of use for peloids. Peloidotherapy stimulates protein synthesis, suppresses arachidonic acid and inflammatory cytokines such as interleukin (IL)-1, tumor necrosis factor-alpha (TNF- $\alpha$ ), leukotriene B4 (LTB4), and prostaglandin F2 (PGF-2) showing antiinflammatory effects. Biological activity is due to the content of sulfur compounds, magnesium, manganese, iron, and humic acid. With the hyperthermic effect, heat shock proteins (HSPs) and cardiac antioxidant defense proteins are stimulated. The increase in plasma beta $(\beta)$-endorphin levels may explain the increased analgesic effect. With the thermal effect, cortisol and catecholamine secretions increase which may explain the anti-inflammatory effect. It is of utmost importance to heat peloids to the correct temperature to yield effective treatment outcomes. ${ }^{[11,12]}$

In the present study, we aimed to investigate peloidotherapy for patients with unilateral $\mathrm{PF}$, as a non-invasive conservative treatment method, and to examine its effect on pain relief and improvement in the functionality and quality of life (QoL).

\section{PATIENTS AND METHODS}

This prospective, observational, pilot study was conducted at Konya Training and Research Hospital, Department of Physical Medicine and Rehabilitation between April 2018 and October 2018. A total of 80 patients (13 males, 67 females; mean age: $47.7 \pm 9.9$ years; range, 28 to 68 years) who were admitted to our clinic with unilateral heel pain and diagnosed with unilateral PF were included. All patients had a Visual Analog Scale-pain (VAS-pain) score of $\geq 4$. Patients with bilateral PF, lumbar disc hernia and rheumatic diseases were excluded from the study. A written informed consent was obtained from each patient. The study protocol was approved by the Selçuk University Faculty of Medicine, Clinical Researches Ethics Committee (No: 2018/66). The study

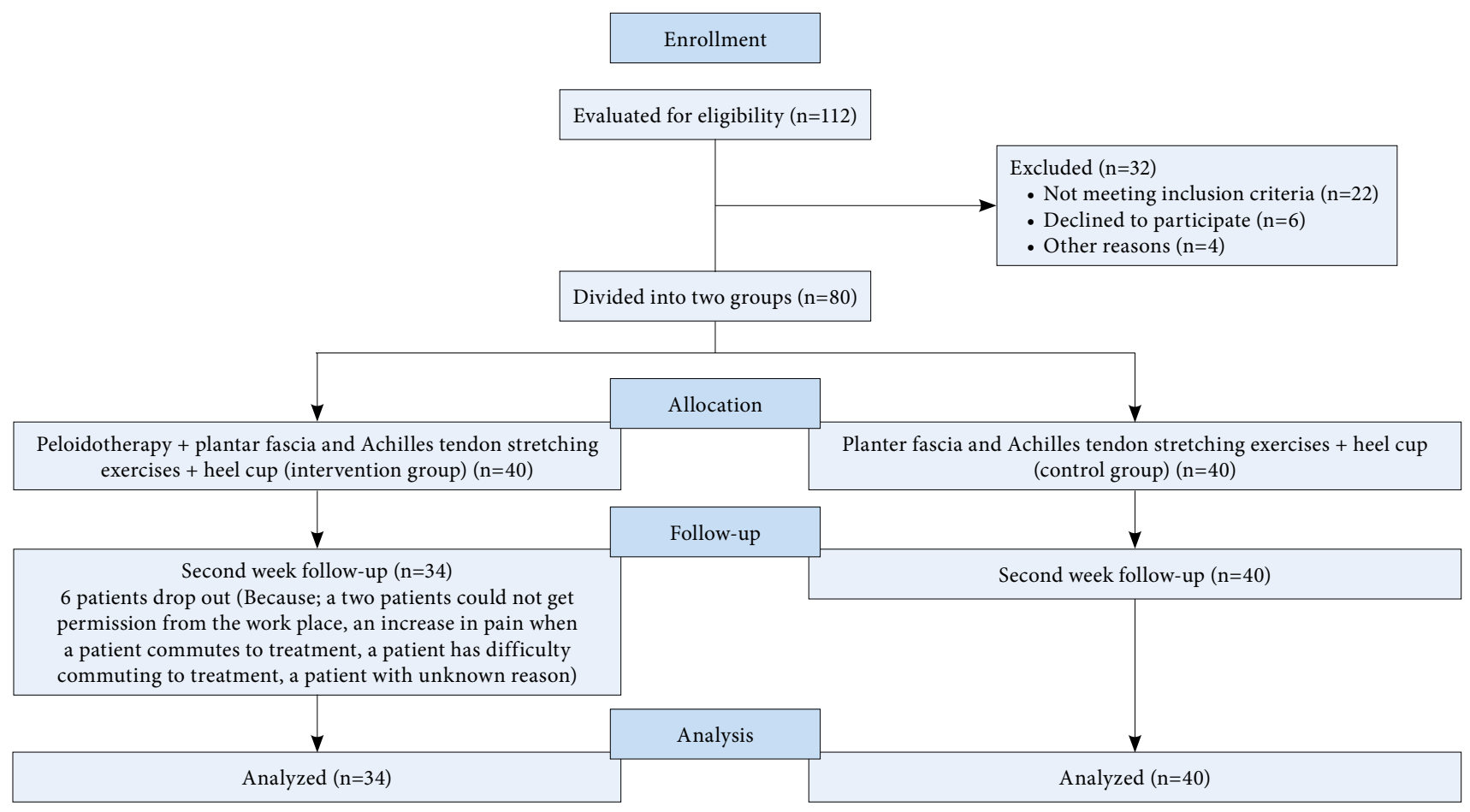

Figure 1. Study flow chart. 


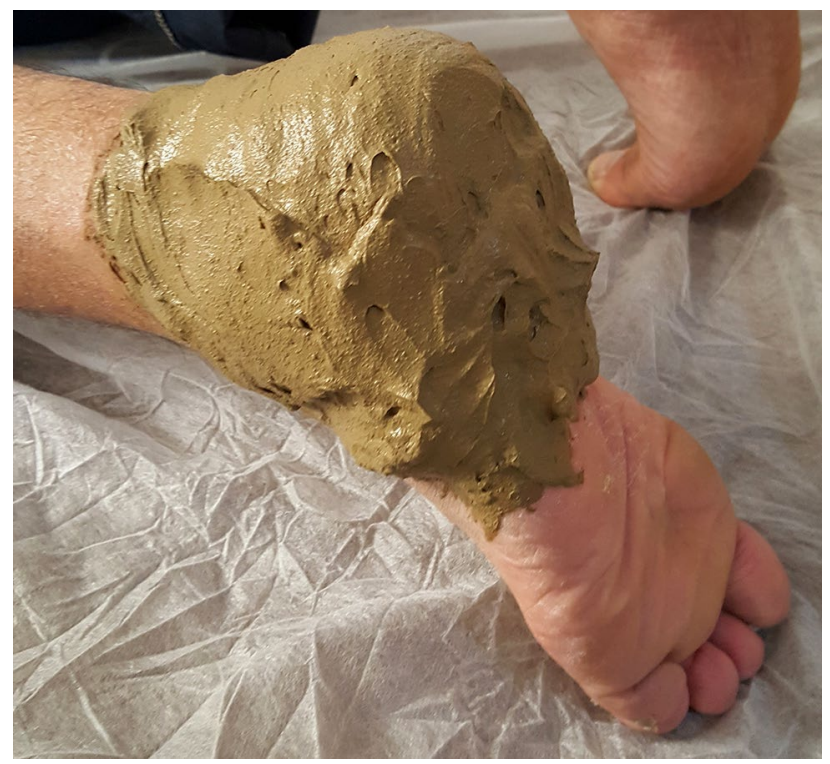

Figure 2. Peloidotherapy application in unilateral plantar fasciitis.

was conducted in accordance with the principles of the Declaration of Helsinki.

\section{Intervention}

The patients were divided into two equal groups. The control group $(n=40)$ was given silicone heel cups and plantar fascia and Achilles tendon stretching exercises, while the study group $(n=40)$ was given peloidotherapy in addition to the same treatment. The study group was evaluated by a physician, while the control group was evaluated by another physician before treatment (baseline) and at the end of the treatment. Both groups of the patients were allowed to take oral paracetamol, as needed. However, they were not allowed to take paracetamol within the first $24 \mathrm{~h}$ before each evaluation session. The study flow chart is shown in Figure 1.

Plantar fascia and Achilles tendon stretching exercises were performed two times per day by the patient themselves, with 10 repeats for $30 \mathrm{sec}$ each in a home-based program. Exercises were shown to patients by an experienced physiotherapist. Peloidotherapy encompassed $1 / 2$ of the foot including the heel and was applied with 2 to $2.5 \mathrm{~cm}$ thickness on the heel, with $45^{\circ} \mathrm{C}$ temperature for $30 \mathrm{~min}$ for a total of 10 sessions. After administration, the foot was wrapped in stretch film and a thick covering with the aim of preserving heat (Figure 2). At the end of treatment, the peloid was cleaned with the scraping method. The content analysis for the medical peloid is shown in Table 1. Pain was evaluated using the VAS-pain. Heel tenderness was assessed using the Heel Tenderness Index (HTI). Quality of life and functional status were evaluated using the Foot and Ankle Outcome Score (FAOS) before treatment and at the end of the second week after treatment by the same physician.

\section{Evaluation parameters}

\section{Visual Analog Scale}

The patients' pain levels were evaluated using a $10 \mathrm{~cm}$ horizontal line. The patients were requested to state the level of their pain. Pain level was $0=$ no pain and $10=$ most severe pain. The point with greatest distance from 0 marked by the patient showed the level of pain felt by the patient. ${ }^{[13]}$

\section{Heel Tenderness Index}

The sensitivity with pressure at the adhesion site of the plantar fascia to the calcaneus was evaluated by the researcher. Points were $0=$ no pain, $1=$ painful, $2=$ painful and tendency to pull back and $3=$ painful and foot fully pulled back. ${ }^{[6]}$

\section{Foot and Ankle Outcome Score}

Function and QoL were evaluated using the FAOS. ${ }^{[14]}$ The FAOS is a 42 -item survey divided into five subsections of pain, other symptoms, daily life activities, sport and recreation functions, and QoL related to feet and ankles. The pain subscale is comprised of nine items, while the other symptoms subscale includes seven items. The daily life activities subscale is consisted of 17 items, the sport and recreation functions subscale is consisted of five items and the QoL concerned to feet and ankles includes four items. Each question is given points on a fivepoint Likert scale (0-4) and each of the five subscale scores are calculated by adding the subscale items. Raw scores are transformed into final points from $0-100$ (from the worst result to the best result). ${ }^{[1,15]}$ The Turkish validity and reliability studies were performed by Karatepe et al. ${ }^{[15]}$ The scales were filled by the researchers.

\section{Statistical analysis}

Statistical analysis was performed using the NCSS (Number Cruncher Statistical System) 2007\&PASS (Power Analysis and Sample Size) 2008 Statistical Software (NCSS LLC, Kaysville, Utah, USA). Descriptive data were expressed in mean \pm standard deviation (SD), median (min-max) or number and frequency. Quantitative data showed 
a normal distribution using the Kolmogorov-Smirnov and Shapiro-Wilk tests. Quantitative data with normal distribution had two-group comparisons using the Student t-test, while the Mann-Whitney $\mathrm{U}$ test was used for two group comparisons of data without normal distribution. For the comparison of qualitative data, the Pearson chi-square test,
Fisher-Freeman-Halton exact test, and Fisher's exact test were used. Intra-group comparisons of data with normal distribution were carried out using the paired samples t-test, while intra-group comparisons of data without normal distribution were performed using the Wilcoxon signed-rank test. A $p$ value of $<0.05$ was considered statistically significant.

\begin{tabular}{|c|c|c|c|}
\hline \multicolumn{4}{|c|}{$\begin{array}{c}\text { TABLE } 1 \\
\text { Chemical analysis of peloid }\end{array}$} \\
\hline Examined parameters & Unit & Method/device & Analysis \\
\hline Color & - & Visual & Light coffee color \\
\hline Smell & - & Sensory & Odorless \\
\hline $\mathrm{pH}$ & - & Potentiometric & 8.75 \\
\hline Water holding capacity & $(\%)\left(105^{\circ} \mathrm{C}\right)$ & Gravimetric & 79.63 \\
\hline Humic acid & $\mathrm{g} / \mathrm{L}$ & Gravimetric & 46.98 \\
\hline Bituminous substances & $\mathrm{g} / \mathrm{L}$ & Gravimetric & 1.62 \\
\hline Hemicellulose, cellulose & $\mathrm{g} / \mathrm{L}$ & Gravimetric & 24.84 \\
\hline Lignin, humin & $\mathrm{g} / \mathrm{L}$ & Gravimetric & 126.23 \\
\hline Dissolved carbohydrates & $\mathrm{g} / \mathrm{L}$ & Gravimetric & 2.64 \\
\hline Hydrogen sulfide & $\mathrm{g} / \mathrm{L}$ & Titrimetric & 0.00 \\
\hline Total of inorganic materials & $\mathrm{g} / \mathrm{L}$ & Gravimetric & $1,147.50$ \\
\hline Total of organic materials & $\mathrm{g} / \mathrm{L}$ & Gravimetric & 202.5 \\
\hline
\end{tabular}

\begin{tabular}{|c|c|c|c|c|c|c|c|c|c|c|c|}
\hline \multicolumn{12}{|c|}{$\begin{array}{c}\text { TABLE } 2 \\
\text { Baseline characteristics of the study population }\end{array}$} \\
\hline & \multicolumn{5}{|c|}{ Study group $(\mathrm{n}=40)$} & \multicolumn{5}{|c|}{ Control group $(\mathrm{n}=40)$} & \multirow[b]{2}{*}{$p$} \\
\hline & $\mathrm{n}$ & $\%$ & Mean \pm SD & Median & Min-Max & $\mathrm{n}$ & $\%$ & Mean \pm SD & Median & Min-Max & \\
\hline Age (year) & & & $50.6 \pm 9.9$ & 50 & $28-65$ & & & $44.9 \pm 9.1$ & 43.5 & $29-68$ & $0.008^{* a}$ \\
\hline Sex & & & & & & & & & & & $0.130^{\mathrm{b}}$ \\
\hline Female & 36 & 90.0 & & & & 31 & 77.5 & & & & \\
\hline Male & 4 & 10.0 & & & & 9 & 22.5 & & & & \\
\hline $\operatorname{BMI}\left(\mathrm{kg} / \mathrm{m}^{2}\right)$ & & & $32.0 \pm 3.9$ & 31.4 & $22.7-41.3$ & & & $30.0 \pm 4.5$ & 29.9 & $20.8-40.6$ & $0.036^{* * b}$ \\
\hline Marital status & & & & & & & & & & & $0.201^{\mathrm{c}}$ \\
\hline Married & 39 & 97.5 & & & & 35 & 87.5 & & & & \\
\hline Single & 1 & 2.5 & & & & 5 & 12.5 & & & & \\
\hline Educational status & & & & & & & & & & & $0.106^{\mathrm{d}}$ \\
\hline Primary school and below & 29 & 72.5 & & & & 22 & 55.0 & & & & \\
\hline Middle school & 1 & 2.5 & & & & 6 & 15.0 & & & & \\
\hline High school and above & 10 & 25.0 & & & & 12 & 30.0 & & & & \\
\hline Employment status & & & & & & & & & & & $0.073^{\mathrm{d}}$ \\
\hline Working & 5 & 12.5 & & & & 13 & 32.5 & & & & \\
\hline Housewife & 31 & 77.5 & & & & 25 & 62.5 & & & & \\
\hline Retired & 4 & 10.0 & & & & 2 & 5.0 & & & & \\
\hline \multicolumn{12}{|l|}{ Disease characteristics } \\
\hline Pain duration (month) & & & $3.4 \pm 1.3$ & 3 & $1-6$ & & & $2.7 \pm 1.5$ & 2.5 & $1-6$ & $0.021^{* * e}$ \\
\hline Which foot & & & & & & & & & & & $0.823^{\mathrm{b}}$ \\
\hline Right foot & 19 & 47.5 & & & & 20 & 50.0 & & & & \\
\hline Left foot & 21 & 52.5 & & & & 20 & 50.0 & & & & \\
\hline
\end{tabular}




\begin{tabular}{|c|c|c|c|c|c|c|c|}
\hline \multirow[b]{3}{*}{ Clinical parameters } & \multicolumn{6}{|c|}{$\begin{array}{c}\text { TABLE } 3 \\
\text { Assessment of functional parameters }\end{array}$} & \multirow[b]{3}{*}{$p$} \\
\hline & \multicolumn{3}{|c|}{ Study group $(\mathrm{n}=40)$} & \multicolumn{3}{|c|}{ Control group $(n=40)$} & \\
\hline & Mean \pm SD & Median & Min-Max & Mean \pm SD & Median & Min-Max & \\
\hline \multicolumn{8}{|l|}{ VAS-pain } \\
\hline Baseline & $8.5 \pm 1.3$ & 9 & $5-10$ & $8.1 \pm 1.7$ & 7 & $4-10$ & $0.001^{\star a}$ \\
\hline After treatment & $6.3 \pm 2.2$ & 7 & $0-10$ & $6.3 \pm 1.9$ & 6.5 & 3-9 & $0.918^{\mathrm{a}}$ \\
\hline$p$ & & $0.001^{\star_{c}}$ & & & $0.001^{\star_{c}}$ & & \\
\hline Pre-post-treatment difference & $-2.0 \pm 2.6$ & -1 & $-10-3$ & $-0.8 \pm 1.0$ & -0.5 & $-3-1$ & $0.024^{\star * b}$ \\
\hline \multicolumn{8}{|l|}{ HTI } \\
\hline Baseline & $1.6 \pm 0.7$ & 2 & $1-3$ & $2.1 \pm 0.8$ & 2 & $1-3$ & $0.003^{\star b}$ \\
\hline After treatment & $1.2 \pm 0.7$ & 1 & $0-2$ & $1.9 \pm 0.8$ & 2 & $0-3$ & $0.001^{\star b}$ \\
\hline$p$ & & $0.010^{* * d}$ & & & $0.008^{* d}$ & & \\
\hline Pre-post-treatment difference & $-0.4 \pm 0.9$ & 0 & $-2-1$ & $-0.3 \pm 0.6$ & 0 & $-2-1$ & 0.412 \\
\hline
\end{tabular}

\begin{tabular}{|c|c|c|c|c|c|c|c|}
\hline \multirow[b]{3}{*}{ Clinical parameters } & \multicolumn{6}{|c|}{$\begin{array}{l}\text { TABLE } 4 \\
\text { Comparison of the Foot and Ankle Outcome Score }\end{array}$} & \multirow[b]{3}{*}{$p$} \\
\hline & \multicolumn{3}{|c|}{ Study group $(\mathrm{n}=40)$} & \multicolumn{3}{|c|}{ Control group $(n=40)$} & \\
\hline & Mean \pm SD & Median & Min-Max & Mean \pm SD & Median & Min-Max & \\
\hline \multicolumn{8}{|l|}{ FAOS pain } \\
\hline Baseline & $43.2 \pm 13.0$ & 40.3 & $5.6-69.5$ & $50.5 \pm 17.0$ & 47.2 & $13.9-86.1$ & $0.033^{\star a}$ \\
\hline After treatment & $53.8 \pm 12.6$ & 52.8 & $36.1-83.3$ & $53.3 \pm 17.5$ & 47.3 & $13.9-85.4$ & $0.870^{\mathrm{a}}$ \\
\hline$p$ & & $0.001^{* c}$ & & & $0.074^{\mathrm{c}}$ & & \\
\hline Pre-post-treatment difference & $10.7 \pm 15.9$ & 8.3 & $-13.9-50$ & $2.7 \pm 9.4$ & 0.5 & $-22.2-37.8$ & $0.011^{\star * b}$ \\
\hline \multicolumn{8}{|l|}{ FAOS symptoms } \\
\hline Baseline & $57.3 \pm 17.7$ & 57.2 & $17.9-82.2$ & $62.1 \pm 18.0$ & 62.5 & $25-92.6$ & $0.231^{\mathrm{a}}$ \\
\hline After treatment & $66.5 \pm 15.0$ & 67.9 & $35.7-92.9$ & $63.2 \pm 17.0$ & 60.7 & $31.5-92.9$ & $0.391^{\mathrm{a}}$ \\
\hline$p$ & & $0.007^{\star c}$ & & & $0.264^{c}$ & & \\
\hline Pre-post-treatment difference & $9.2 \pm 18.8$ & 5.4 & $-21.4-60.7$ & $1.1 \pm 6.0$ & 0 & $-21.4-17.9$ & $0.108^{\mathrm{b}}$ \\
\hline \multicolumn{8}{|l|}{ FAOS ADL } \\
\hline Baseline & $45.1 \pm 13.6$ & 42.7 & $17.7-73.5$ & $53.3 \pm 17.9$ & 53.7 & $22.3-86.8$ & $0.024^{* * a}$ \\
\hline After treatment & $57.6 \pm 17.3$ & 58.1 & $28-95.6$ & $54.1 \pm 17.0$ & 55.8 & $20-86.8$ & $0.381^{\mathrm{a}}$ \\
\hline$p$ & & $0.001^{\star c}$ & & & $0.579^{c}$ & & \\
\hline Pre-post-treatment difference & $13.7 \pm 16.5$ & 9.6 & $-13.2-61.8$ & $0.8 \pm 8.5$ & 0 & $-26.5-36.8$ & $0.001^{\star b}$ \\
\hline \multicolumn{8}{|l|}{ FAOS SPORT } \\
\hline Baseline & $30.9 \pm 16.2$ & 30 & $0-70$ & $44.2 \pm 23.0$ & 40 & $10-95$ & $0.004^{\star a}$ \\
\hline After treatment & $40.2 \pm 22.1$ & 40 & $0-80$ & $46.0 \pm 21.9$ & 40 & $15-95$ & $0.258^{\mathrm{a}}$ \\
\hline$p$ & & $0.008^{\star c}$ & & & $0.188^{c}$ & & \\
\hline Pre-posttreatment difference & $9.3 \pm 19.1$ & 7.5 & $-30-55$ & $1.8 \pm 8.5$ & 0 & $-35-20$ & $0.109^{\mathrm{b}}$ \\
\hline \multicolumn{8}{|l|}{ FAOS QoL } \\
\hline Baseline & $25.0 \pm 18.3$ & 25 & $0-75$ & $34.0 \pm 13.1$ & 37.5 & $12-62.5$ & $0.013^{\star * a}$ \\
\hline After treatment & $33.1 \pm 15.4$ & 31.3 & $0-75$ & $37.6 \pm 14.5$ & 37.5 & $18.8-87.5$ & $0.201^{\mathrm{a}}$ \\
\hline$p$ & & $0.021^{\star * c}$ & & & $0.002^{* c}$ & & \\
\hline Pre-post-treatment difference & $8.6 \pm 20.8$ & 6.3 & $-50-62.5$ & $3.5 \pm 6.6$ & 1.1 & $-8.5-31.3$ & $0.077^{\mathrm{b}}$ \\
\hline
\end{tabular}




\section{RESULTS}

Of a total of 80 patients divided into two equal groups, one patient in the study group did not meet the time of treatment, two patients could not get permission from the work place, one patient had an increase in pain with treatment, one patient had difficulty in attending to treatment, and one patient had unknown reasons that were all excluded from the study. Peloidotherapy was well-tolerated by the patients in the study group and the patients did not experience any side effects. The study was completed with 34 patients $(n=34)$ in the study group and 40 patients $(n=40)$ in the control group.

There were no statistically significant differences between the groups in terms of sex, marital status, education status, employment status, and laterality rates (right or left) of the treated feet $(\mathrm{p}>0.05)$ (Table 2).

The study group showed statistically significant improvements for all parameters after treatment compared to baseline $(p<0.05)$. The control group showed statistically significant improvements in the VAS-pain, HTI, and FAOS-QoL subscale parameters after treatment compared to baseline $(\mathrm{p}<0.05)$. The study group showed a better improvement in the VAS-pain, FAOS-pain, and FAOS-work daily life subscales than the control group $(\mathrm{p}<0.05)$ (Tables 3 and 4).

\section{DISCUSSION}

In our study, for patients with unilateral PF, both exercise and exercise + peloidotherapy groups were shown to have reduced pain, increased functionality and improvements in QoL. The combination of peloidotherapy and exercise was superior compared to the group with exercise alone. To the best of our knowledge, this study is the first in the literature regarding the use of peloidotherapy as a conservative treatment approach for patients with PF.

In the literature, efficacy was shown for plantar fascia and Achilles tendon stretching exercises. One study found plantar fascia stretching exercises to be more effective to radial shock wave treatment. ${ }^{[16]}$ Another study showed that therapeutic ultrasound combined with plantar fascia stretching exercises were effective in reducing pain and functional healing. ${ }^{[17]}$ A recent study showed that hip, foot, and ankle stretching and strengthening exercises were effective in reducing pain and increasing functionality ${ }^{[18]}$ A study comparing radial shock wave treatment alone and radial shock wave + plantar fascia stretching exercises found the combination treatment to be more effective on the chronic symptoms of plantar fasciopathy by reducing pain and improving functionality. ${ }^{[19]}$ A three-branch study evaluating foot and hip stretching and strengthening exercises found pain to reduce and functionality to increase in PF patients in all exercise groups. ${ }^{[20]}$ Furthermore, a study comparing joint mobilization and stretching exercise combinations with steroid injection for PF patients showed that the exercise group had reduced pain and increased functionality up to a year. ${ }^{[21]}$ In our study, Achilles tendon and plantar fascia stretching exercises were also shown to reduce pain and improve certain functional parameters.

The efficacy of peloidotherapy for musculoskeletal system diseases has been shown in many studies. A retrospective study by Kardeş et al. ${ }^{[22]}$ showed that, in patients aged 65 years and older with generalized, knee, low back, neck and hand osteoarthritis (OA), peloidotherapy and hydrotherapy treatments reduced pain and provided functional improvements for patients. A single-blind, randomized-controlled study comparing efficacy of peloidotherapy with hot compress treatment for knee OA observed that peloidotherapy reduced pain and improved QoL up to three months. ${ }^{[23]}$ A study by Kasapoğlu Aksoy et al. ${ }^{[24]}$ compared the efficacy of home exercises and peloidotherapy with home exercises for hand OA. The combination of peloidotherapy and home exercises showed positive effects on pain control, QoL, hand functions, and muscle strength. A double-blind, randomized-controlled study assessing the efficacy of two different peloids for knee OA divided a total of 60 patients into two groups. ${ }^{[25]}$ The patients had two different peloids applied at $42^{\circ} \mathrm{C}$ temperature for 10 sessions. Evaluations after 12 weeks showed reduced pain in patients and improvements in functions and QoL in both groups. Dischereit et al. ${ }^{[26]}$ showed positive effects on reduced pain and improvements in functional status for patients treated with peloid baths in addition to physical rehabilitation treatments for patients with ankylosing spondylitis, rheumatoid arthritis, and OA. A single-blind, randomized-controlled study including 65 patients with chronic lateral epicondylitis administered lateral epicondylitis bandage for six weeks + peloidotherapy with $20 \mathrm{~min} / \mathrm{session}$ at $47^{\circ} \mathrm{C}$ for a total of 10 sessions over two weeks to Group $1(n=33)$. [27] Group $2(n=32)$ had only lateral epicondylitis bandage treatment for six weeks. Evaluations at the end of treatment and at six weeks showed that peloidotherapy reduced pain and improved QoL 
and functionality of lateral epicondylitis patients. Another single-blind, randomized study evaluating the short-term efficacy of peloidotherapy for carpal tunnel syndrome recommended peloidotherapy as a complementary treatment method for carpal tunnel syndrome. ${ }^{[28]}$ There are reviews and meta-analyses showing the efficacy of peloidotherapy and Spa treatments for many diseases such as knee OA, ankylosing spondylitis, psoriatic arthritis, hand OA, rheumatoid arthritis and chronic low back pain. ${ }^{[29-35]}$ In our study, we found the reduction in pain and improvements in QoL and functional status in the peloid and exercise treatment group to be statistically significantly superior to the group with only exercise. This can be explained by the analgesic and anti-inflammatory effects of peloidotherapy.

Peloidotherapy is usually performed as heat applications, and heat transfer is one of the most optimal tools. It is simultaneously a thermotherapeutic intervention. The beneficial effects of peloids are related to physical, chemical, and biological properties. The water-soluble organic and inorganic content of peloids may be absorbed by skin, playing a role in its efficacy. ${ }^{[36]}$ Gyarmati et al., ${ }^{[37]}$ in a single-blind, randomized study evaluating the chemical effects of peloid for hand OA patients divided 47 patients into two groups. Group $1(\mathrm{n}=23)$ had direct peloid administration to both hands, while Group $2(n=24)$ had peloid administration to both hands while wearing nylon gloves at $42^{\circ} \mathrm{C}$ temperature for $20 \mathrm{~min} /$ day for a total of three weeks. The patients were assessed before treatment, after treatment, and at 16 weeks. The 16 -week assessment showed statistically significantly better improvements in the direct peloid group for VAS-pain evaluation and swollen joint numbers. The chemical efficacy of peloid for pain and QoL in hand OA patients was, therefore, proven. A study including 42 patients aged 60 years and older with primary knee OA administered whole-body peloid administration with a brush at 40 to $42^{\circ} \mathrm{C}$ temperature for 10 sequential days, followed by 45 to $60 \mathrm{~min}$ solarium, then 15 -min peloid bath at 38 to $40^{\circ} \mathrm{C}$ temperature. ${ }^{[38]}$ Finally, the mud remnants were removed with a thermal water jet shower $\left(38\right.$ to $40^{\circ} \mathrm{C}$ ) for 2 min. Patients had a statistically significant increase in knee flexion extension angles, reduced pain, and statistically significant improvements in functional status and QoL. Assessment of blood samples taken at the end of treatment showed a reduction in proinflammatory cytokine IL-8 and anti-inflammatory cytokine transforming growth factor- $\beta$ (TGF- $\beta$ ) levels. The reduction in IL- 8 was greater, and the inflammatory index was observed to reduce. There was a reduction in pain in parallel with the reduction in IL-8 concentration, while there were improvements in joint mobility and functionality in parallel with the reduction in TGF- $\beta$ levels. Additionally, neutrophil was shown to increase the phagocytic activity. In another study, after 10 sessions of peloidotherapy applied to 25 patients with primary knee OA, blood samples examined for inflammatory cytokines showed reductions in serum IL-1 $\beta$, TNF- $\alpha$, IL- 8 , IL- 6 , and TGF- $\beta$ levels and, similarly, a reduction in extracellular heat shock protein 72 (eHsp72) levels. Additionally, there was a statistically significant increase in serum cortisol levels. Peloidotherapy was shown to have systemic anti-inflammatory effect and a role in neuroendocrine immune regulation in OA patients. ${ }^{[39]}$ A study assessing the effect of peloid bath treatment for patients with chronic low back pain showed that some protein changes were induced, playing a role in modulation of gene expression, angiogenesis, tissue repair, and acute and chronic inflammatory responses. ${ }^{[40]}$ Peloids are not only effective with their thermal effects, but also with their chemical properties. The chemical activity of peloids may have a role in analgesic, anti-inflammatory, and tissue repair implications.

The main limitations of this study are that it is not a randomized-controlled study, there was no placebo control group, and no mid to long-term follow-up. In addition, a radiological imaging method such as ultrasound or magnetic resonance imaging was unable to be used at the time of enrollment. The small size of the sample can be another limitation.

In conclusion, these results indicate that, for unilateral PF patients, peloid + plantar fascia and Achilles tendon stretching exercises + heel cup treatment are more effective in reducing pain and improving functional status and QoL than plantar fascia + Achilles tendon stretching exercises + heel cup treatment. Peloidotherapy may be recommended as a non-invasive conservative treatment approach for PF patients. Nevertheless, there is a need for further well-designed, large-scale, randomized-controlled clinical studies with mid- to long-term follow-up.

\section{Declaration of conflicting interests}

The authors declared no conflicts of interest with respect to the authorship and/or publication of this article.

\section{Funding}

The authors received no financial support for the research and/or authorship of this article. 


\section{REFERENCES}

1. Trojian T, Tucker AK. Plantar fasciitis. Am Fam Physician 2019;99:744-50.

2. Lemont H, Ammirati KM, Usen N. Plantar fasciitis: A degenerative process (fasciosis) without inflammation. J Am Podiatr Med Assoc 2003;93:234-7.

3. Goff JD, Crawford R. Diagnosis and treatment of plantar fasciitis. Am Fam Physician 2011;84:676-82.

4. Chen $\mathrm{CM}$, Lee M, Lin CH, Chang $\mathrm{CH}$, Lin $\mathrm{CH}$. Comparative efficacy of corticosteroid injection and non-invasive treatments for plantar fasciitis: A systematic review and meta-analysis. Sci Rep 2018;8:4033.

5. Salvioli S, Guidi M, Marcotulli G. The effectiveness of conservative, non-pharmacological treatment, of plantar heel pain: A systematic review with meta-analysis. Foot (Edinb) 2017;33:57-67.

6. Ordahan B, Türkoğlu G, Karahan AY, Akkurt HE. Extracorporeal shockwave therapy versus kinesiology taping in the management of plantar fasciitis: A randomized clinical trial. Arch Rheumatol 2017;32:227-33.

7. Dedes V, Tzirogiannis K, Polikandrioti M, Dede AM, Nikolaidis C, Mitseas A, et al. Radial extra corporeal shockwave therapy versus ultrasound therapy in the treatment of plantar fasciitis. Acta Inform Med 2019;27:45-9.

8. Ersen Ö, Koca K, Akpancar S, Seven MM, Akyıldız F, Yıldız $\mathrm{Y}$, et al. A randomized-controlled trial of prolotherapy injections in the treatment of plantar fasciitis. Turk J Phys Med Rehabil 2017;64:59-65.

9. Fraser JJ, Corbett R, Donner C, Hertel J. Does manual therapy improve pain and function in patients with plantar fasciitis? A systematic review. J Man Manip Ther 2018;26:55-65.

10. Ge W, Leson C, Vukovic C. Dry cupping for plantar fasciitis: A randomized controlled trial. J Phys Ther Sci 2017;29:859-62.

11. Groven MD. Peat therapeutics and balneotherapy. In: Pizzorno JE, Murray MT, editors. Textbook of natural medicine. Chapter 45. 4th ed. St. Louis: Churchill Livingstone, Elsevier; 2013. p. 385-94.

12. Odabasi E, Turan M, Erdem H, Tekbas F. Does mud pack treatment have any chemical effect? A randomized controlled clinical study. J Altern Complement Med 2008;14:559-65.

13. Price DD, McGrath PA, Rafii A, Buckingham B. The validation of visual analogue scales as ratio scale measures for chronic and experimental pain. Pain 1983;17:45-56.

14. Roos EM, Brandsson S, Karlsson J. Validation of the foot and ankle outcome score for ankle ligament reconstruction. Foot Ankle Int 2001;22:788-94.

15. Karatepe AG, Günaydin R, Kaya T, Karlibaş U, Özbek G. Validation of the Turkish version of the foot and ankle outcome score. Rheumatol Int 2009;30:169-73.

16. Rompe JD, Cacchio A, Weil L Jr, Furia JP, Haist J, Reiners V, et al. Plantar fascia-specific stretching versus radial shockwave therapy as initial treatment of plantar fasciopathy. J Bone Joint Surg [Am] 2010;92:2514-22.
17. Shashua A, Flechter S, Avidan L, Ofir D, Melayev A, Kalichman L. The effect of additional ankle and midfoot mobilizations on plantar fasciitis: A randomized controlled trial. J Orthop Sports Phys Ther 2015;45:265-72.

18. Çil ET, Şaylı U, Subaşı F. Outpatient vs home management protocol results for plantar fasciitis. Foot Ankle Int 2019;40:1295-303.

19. Rompe JD, Furia J, Cacchio A, Schmitz C, Maffulli N. Radial shock wave treatment alone is less efficient than radial shock wave treatment combined with tissue-specific plantar fascia-stretching in patients with chronic plantar heel pain. Int J Surg 2015;24:135-42.

20. Kamonseki DH, Gonçalves GA, Yi LC, Júnior IL. Effect of stretching with and without muscle strengthening exercises for the foot and hip in patients with plantar fasciitis: A randomized controlled single-blind clinical trial. Man Ther 2016;23:76-82.

21. Celik D, Kuş G, Sırma SÖ. Joint mobilization and stretching exercise vs steroid injection in the treatment of plantar fasciitis: A randomized controlled study. Foot Ankle Int 2016;37:150-6.

22. Kardeş S, Karagülle M, Geçmen İ, Adıgüzel T, Yücesoy $\mathrm{H}$, Karagülle MZ. Outpatient balneological treatment of osteoarthritis in older persons: A retrospective study. Z Gerontol Geriatr 2019;52:164-71.

23. Sarsan A, Akkaya N, Ozgen M, Yildiz N, Atalay NS, Ardic F. Comparing the efficacy of mature mud pack and hot pack treatments for knee osteoarthritis. J Back Musculoskelet Rehabil 2012;25:193-9.

24. Kasapoğlu Aksoy M, Altan L, Eröksüz R, Metin Ökmen B. The efficacy of peloid therapy in management of hand osteoarthritis: A pilot study. Int J Biometeorol 2017;61:2145-52.

25. Király M, Kővári E, Hodosi K, Bálint PV, Bender T. The effects of Tiszasüly and Kolop mud pack therapy on knee osteoarthritis: A double-blind, randomised, non-inferiority controlled study. Int J Biometeorol 2020;64:943-50.

26. Dischereit G, Goronzy JE, Müller-Ladner U, Fetaj S, Lange $U$. Effects of serial mud baths on inflammatory rheumatic and degenerative diseases. Z Rheumatol 2019;78:143-54.

27. Ökmen BM, Eröksüz R, Altan L, Aksoy MK. Efficacy of peloid therapy in patients with chronic lateral epicondylitis: A randomized, controlled, single blind study. Int J Biometeorol 2017;61:1965-72.

28. Metin Ökmen B, Kasapoğlu Aksoy M, Güneş A, Eröksüz R, Altan L. Effectiveness of PELOID therapy in carpal tunnel syndrome: A randomized controlled single blind study. Int J Biometeorol 2017;61:1403-10.

29. Antonelli M, Donelli D, Fioravanti A. Effects of balneotherapy and spa therapy on quality of life of patients with knee osteoarthritis: A systematic review and metaanalysis. Rheumatol Int 2018;38:1807-24.

30. Forestier R, Erol Forestier FB, Francon A. Spa therapy and knee osteoarthritis: A systematic review. Ann Phys Rehabil Med 2016;59:216-26.

31. Xiang J, Wu D, Li J. Clinical efficacy of mudpack therapy in treating knee osteoarthritis: A meta-analysis of randomized controlled studies. Am J Phys Med Rehabil 2016;95:121-31. 
32. Cozzi F, Ciprian L, Carrara M, Galozzi P, Zanatta E, Scanu A, et al. Balneotherapy in chronic inflammatory rheumatic diseases-a narrative review. Int J Biometeorol 2018;62:2065-71.

33. Fortunati NA, Fioravanti A, Seri G, Cinelli S, Tenti S. May spa therapy be a valid opportunity to treat hand osteoarthritis? A review of clinical trials and mechanisms of action. Int J Biometeorol 2016;60:1-8.

34. Verhagen AP, Bierma-Zeinstra SM, Boers M, Cardoso JR, Lambeck J, de Bie R, et al. Balneotherapy (or spa therapy) for rheumatoid arthritis. Cochrane Database Syst Rev 2015;2015:CD000518.

35. Karagülle $M$, Karagülle $M Z$. Effectiveness of balneotherapy and spa therapy for the treatment of chronic low back pain: A review on latest evidence. Clin Rheumatol 2015;34:207-14.

36. Gálvez I, Torres-Piles S, Ortega-Rincón E. Balneotherapy, immune system, and stress response: A hormetic strategy? Int J Mol Sci 2018;19:1687.
37. Gyarmati N, Kulisch Á, Németh A, Bergmann A, Horváth J, Mándó Z, et al. Evaluation of the effect of Hévíz mud in patients with hand osteoarthritis: A randomized, controlled, single-blind follow-up study. Isr Med Assoc J 2017;19:177-82.

38. Gálvez I, Torres-Piles S, Ortega E. Innate/inflammatory bioregulation and clinical effectiveness of whole-body hyperthermia (balneotherapy) in elderly patients with osteoarthritis. Int J Hyperthermia 2018;35:340-7.

39. Ortega E, Gálvez I, Hinchado MD, Guerrero J, MartínCordero L, Torres-Piles S. Anti-inflammatory effect as a mechanism of effectiveness underlying the clinical benefits of pelotherapy in osteoarthritis patients: Regulation of the altered inflammatory and stress feedback response. Int J Biometeorol 2017;61:1777-85.

40. Angioni MM, Denotti A, Pinna S, Sanna C, Montisci F, Dessole G, et al. Spa therapy induces clinical improvement and protein changes in patients with chronic back pain. Reumatismo 2019;71:119-31. 